\title{
Development and Preliminary Psychometric Evaluation of the Self-Perceptions in Rehabilitation Questionnaire (SPIRQ) for Brain Injury Rehabilitation
}

\author{
Tamara Ownsworth, Ea Stewart, Jennifer Fleming, Janelle Griffin, \\ Ann Maree Collier, Julia Schmidt
}

\section{MeSH TERMS}

- awareness

- brain injuries

- psychometrics

- questionnaires

- self concept
Tamara Ownsworth, PhD, is Associate Professor, School of Applied Psychology and Griffith Institute for Health, Griffith University, Mt. Gravatt, Queensland, Australia.

Ea Stewart, PsyD, is Senior Research Assistant, School of Applied Psychology and Griffith Institute for Health, Griffith University, Mt. Gravatt, Queensland, Australia.

Jennifer Fleming, PhD, is Conjoint Associate Professor, School of Health and Rehabilitation Sciences, The University of Queensland, St. Lucia, Queensland 4072 Australia; Conjoint Associate Professor, Occupational Therapy Department, Princess Alexandra Hospital, Woolloongabba, Queensland, Australia; and Associate Professor, Centre for Functioning and Health Research, Metro South Health Services District, Buranda, Queensland, Australia; j.fleming@uq.edu.au

Janelle Griffin, M.Phil, is Team Leader, Occupational Therapy Department, Princess Alexandra Hospital, Woolloongabba, Queensland, Australia.

Ann Maree Collier is Occupational Therapist, Occupational Therapy Department, Princess Alexandra Hospital, Woolloongabba, Queensland, Australia.

Julia Schmidt is PhD Student, School of Health and Rehabilitation Sciences, The University of Queensland, St. Lucia, Queensland, Australia, and Occupational Therapist, Royal Rehabilitation Centre, Sydney, New South Wales, Australia.
OBJECTIVE. The Self-Perceptions in Rehabilitation Questionnaire (SPIRQ) is a brief measure developed to monitor client self-perceptions, motivation, and emotional reactions throughout rehabilitation. We describe the SPIRQ's development and preliminary psychometric evaluation.

METHOD. One hundred five adults with traumatic brain injury attending two brain injury rehabilitation units completed the SPIRQ during occupational therapy sessions. A subset $(n=33)$ completed the SPIRQ twice over a 5- to 7-day interval to examine test-retest reliability.

RESULTS. Exploratory factor analysis yielded three factors: Changes in Self and Life Plans, Self in Rehabilitation, and Emotional Reactions. Their internal consistency was sound $(\alpha S=.72-.83)$. Test-retest reliability was generally acceptable ( $r s=.67-.81)$, and scores did not significantly change between testing occasions $(p>.05)$. CONCLUSION. We found preliminary support for the SPIRQ scales' reliability and construct validity. Future empirical evaluation and potential clinical applications of the SPIRQ in occupational therapy are discussed.

Ownsworth, T., Stewart, E., Fleming, J., Griffin, J., Collier, A. M., \& Schmidt, J. (2013). Development and preliminary psychometric evaluation of the Self-Perceptions in Rehabilitation Questionnaire (SPIRQ) for brain injury rehabilitation. American Journal of Occupational Therapy, 67, 336-344. http://dx.doi.org/10.5014/ajot.2013.007625

T raumatic brain injury (TBI) leads to diverse physical, cognitive, and behavioral impairments that can affect the capacity to resume valued preinjury occupations and occupational roles (Tate $\&$ Broe, 1999). Adjustment to TBI is influenced by how people appraise their injury-related impairments and the extent to which they recognize the impact of the TBI on their current and future functioning (Hart, Seignourel, \& Sherer, 2009). Self-perceptions of the everyday consequences of TBI can influence motivation for therapy and emotional adjustment to postinjury circumstances (Fleming, Strong, \& Ashton, 1998). These self-perceptions and related changes in motivation and emotional status need to be monitored in rehabilitation to assist occupational therapists in determining a client's readiness for particular components of therapy (e.g., goal setting) and to signal potential issues that may hinder therapy progress (Ownsworth \& Clare, 2006). In this article, we describe the development and preliminary psychometric investigation of the Self-Perceptions in Rehabilitation Questionnaire (SPIRQ), which was developed for administration to adults with TBI during rehabilitation.

Impaired self-awareness can pose a significant barrier to rehabilitation progress and adjustment after TBI (Abreu et al., 2001; Fleming, Winnington, McGillvray, Tatarevic, \& Ownsworth, 2006). Research has indicated that impaired self-awareness is associated with lower motivation for rehabilitation (Fleming et al., 1998; Lam, McMahon, Priddy, \& Gehred-Schultz, 1988), 
reduced use of coping strategies (Ownsworth, McFarland, \& Young, 2000), and poorer psychosocial outcomes (Sherer, Bergloff, Levin, et al., 1998). A systematic review of 12 studies involving participants with mixed etiology of brain injury identified that people with greater self-awareness generally achieved more favorable rehabilitation outcomes (Ownsworth \& Clare, 2006).

Self-awareness typically improves with time since injury and is facilitated by participation in real-life tasks in a familiar environment after hospital discharge (Dirette, 2002; Fleming \& Strong, 1999). However, the development of self-awareness is often accompanied by increased symptoms of depression and anxiety (Godfrey, Partridge, Knight, \& Bishara, 1993), which can in turn impede community reintegration (Felmingham, Baguley, \& Crooks, 2001; Ownsworth et al., 2011). Such findings underscore the need to monitor the emergence of awareness and associated changes in motivation and emotional distress during the postacute rehabilitation phase.

Despite growing interest in the implications of impaired self-awareness, its formal assessment in clinical practice is typically limited to the start and end of rehabilitation programs. Semistructured interviews such as the Self-Awareness of Deficits Interview (SADI; Fleming, Strong, \& Ashton, 1996) provide quantitative and qualitative data concerning self-perceptions of current and future functioning but are time consuming and therefore not practical for repeated administration throughout rehabilitation. The Canadian Occupational Performance Measure (COPM; Law et al., 1998) uses an interview approach to measure self-perceptions of and satisfaction with performance on individualized occupational goals. However, the COPM does not capture selfperceptions of broader functions such as adaptation to injury, motivation for rehabilitation, or emotional adjustment.

An alternative approach is the use of questionnairebased measures of self-awareness. These include the Patient Competency Rating Scale (Prigatano et al., 1986) and the Awareness Questionnaire (Sherer, Bergloff, Boake, High, \& Levin, 1998), which compare client selfratings with ratings of significant others and have the key advantage of brevity. Various factors, however, influence the extent to which significant-other ratings reflect a true measure of a client's functional status, including familiarity with the person before and after the TBI and emotional issues such as denial and stress (Fleming et al., 1996).

A third option for assessing self-awareness involves behavioral observation of error recognition, self-correction, and strategy use in a functional activity (e.g., Abreu et al., 2001; Ownsworth, Fleming, Desbois, Strong, \& Kuipers, 2006). This method typically does not reflect clients' subjective understanding of their TBI-related limitations, because these internal processes cannot be directly inferred from behavioral observations.

To have clinical utility for administration throughout hospital-based rehabilitation, a tool measuring change in self-perceptions needs to be brief and capture key issues relevant to adjustment to TBI, namely, self-perceived functioning, motivation, and emotional reactions. We developed the SPIRQ for this purpose. Because of its brevity, the SPIRQ is feasible to administer on a periodic basis and may thus support occupational therapists in identifying the timing and pattern of changes. In turn, therapists may be better informed about clients' current readiness for particular therapy components (e.g., clients who do not perceive any changes in their abilities may find it difficult to engage in goal setting) and the need to address issues that could impede progress in rehabilitation (e.g., a lack of understanding of the benefits of rehabilitation). Moreover, assessing clients' current emotional reactions on the SPIRQ periodically throughout rehabilitation may serve as a useful screen for occupational therapists to detect signs of emotional distress that require further assessment by a psychologist.

The development of the SPIRQ items was supported by the same model of self-awareness that guided the development of the SADI (Fleming et al., 1996). We developed a set of items to assess the self-perceived impact of postinjury changes on current functioning and the need for compensatory strategies (Current Self scale). Another set of items was developed to reflect awareness of the impact of deficits on future functioning and the perceived need to modify plans in life (Future Self scale). We also developed items focused on assessing the perceived benefits of participating in rehabilitation (Self in Rehabilitation scale), which is a key aspect of motivation for change (Lam et al., 1988). Finally, we developed a set of items to assess common signs of emotional distress after TBI (Emotional Reactions scale), including depression (hopelessness and low self-worth), anxiety (worry), and reduced self-efficacy (Ownsworth, Fleming, Stewart, \& Griffin, 2009).

Our main aims in this initial study were to examine the factor structure, internal consistency, and test-retest reliability of the SPIRQ. We hypothesized that factor analysis would support the conceptual structure of the SPIRQ and that each of the four scales would demonstrate acceptable internal consistency $(\alpha>.70$; George $\&$ Mallery, 2003). We further hypothesized that the SPIRQ 
would demonstrate satisfactory test-retest reliability $(r>$ .70; Nunnally, 1967) and that scores would not significantly differ between the two assessment sessions over an interval of approximately $1 \mathrm{wk}$. A further aim was to examine the associations between the SPIRQ scales and identify whether responses on the SPIRQ vary according to injury characteristics.

\section{Method}

\section{Research Design}

We used a cross-sectional design to examine the psychometric properties of the SPIRQ on the basis of a single administration. A repeated-measures component was incorporated to assess the SPIRQ's test-retest reliability over a 5- to 7-day reassessment interval. Ethical clearance was obtained from relevant hospital and university ethics committees, and appropriate consent procedures were followed.

\section{Participants}

Occupational therapists working in inpatient or outpatient brain injury rehabilitation at major metropolitan hospitals in Brisbane, Queensland, and Sydney, New South Wales, Australia, were asked to administer the SPIRQ to patients with TBI who met the study eligibility criteria. The inclusion criteria included having been diagnosed with TBI within the past $12 \mathrm{mo}$; having adequate receptive and expressive communication skills; having been assessed as being out of posttraumatic amnesia (PTA); and being age 18-65 yr. Eligible participants were identified by their treating occupational therapist and approached by the same therapist to participate in the study.

\section{Instrument}

We generated items for the SPIRQ, with the initial pool of items developed on the basis of various models of metacognition (Fleming et al., 1996; Ownsworth et al., 2000; Toglia \& Kirk, 2000) as well as clinical experience. Feedback regarding the item suitability and feasibility of administering the measure was provided by six occupational therapists at the Brisbane Brain Injury Rehabilitation Unit (BIRU) who piloted the SPIRQ with 10 patients during an occupational therapy session. Some minor changes to the wording and format were made on the basis of therapist and patient feedback.

The SPIRQ comprises 20 items across four miniscales that are designed to measure clients' self-perceptions of injury, perceived benefits of rehabilitation, and emotional reactions throughout inpatient or outpatient rehabilitation. The SPIRQ items are presented in Table 1, according to each scale (i.e., Current Self, Future Self,

\section{Table 1. Self-Perceptions in Rehabilitation Questionnaire Items}

\begin{tabular}{|c|c|}
\hline Scale and Item No. & Item \\
\hline \multicolumn{2}{|l|}{ Current Self (5 Items) } \\
\hline 2 & Some things are different about me now as compared with before my brain injury. \\
\hline 7 & I feel that I have made a full recovery from my brain injury. \\
\hline 11 & I manage everyday tasks the same as how I used to before my brain injury. \\
\hline 14 & I need to use more strategies now than before my brain injury (e.g., memory aids, do things one at a time). \\
\hline 20 & Other people have noticed changes in me or my abilities since my brain injury. \\
\hline \multicolumn{2}{|l|}{ Future Self (4 Items) } \\
\hline 6 & My brain injury will affect how well I can do the things I want to in life. \\
\hline 9 & My brain injury will still be having an effect on my life in 6 months time. \\
\hline 16 & I have changed some of my future plans due to the effects of my brain injury. \\
\hline 18 & I am concerned about any long-term effects my brain injury might have. \\
\hline \multicolumn{2}{|c|}{ Self in Rehabilitation (5 Items) } \\
\hline 1 & Rehabilitation is helping me to understand my brain injury. \\
\hline 4 & I would be back to normal if I was allowed to return to all the things I used to do (e.g., driving, work, playing sports) \\
\hline 8 & I am learning how to cope with the effects of my brain injury in rehabilitation. \\
\hline 13 & I am working on areas that are important to me in rehabilitation. \\
\hline 17 & Rehabilitation is helping me to achieve my goals. \\
\hline \multicolumn{2}{|c|}{ Emotional Reactions (6 Items) } \\
\hline 3 & When I think about the future I feel uneasy. \\
\hline 5 & I have confidence in my abilities. \\
\hline 10 & I worry about my progress in rehabilitation. \\
\hline 12 & I feel hopeful about the future. \\
\hline 15 & I feel good about myself. \\
\hline 19 & I feel like I can't do anything right. \\
\hline
\end{tabular}


Self in Rehabilitation, and Emotional Reactions). Each SPIRQ item is rated on a 6-point Likert scale (ranging from 1 = strongly disagree to $6=$ strongly agree), and six negatively worded items (Items 4, 5, 7, 11, 12, and 15) are reversed before deriving scale scores. Higher scores on each scale reflect greater acknowledgment of the consequences of TBI, increased perceived benefits of rehabilitation, and greater emotional distress. No total score is calculated for the SPIRQ.

\section{Procedures and Data Collection}

Occupational therapists received training on the administration of the SPIRQ before study commencement and at regular staff meetings to ensure consistency of administration. For the internal consistency analysis, all occupational therapists in brain injury rehabilitation administered the SPIRQ to their own clients at the beginning of an occupational therapy session. For the test-retest reliability analysis, occupational therapists at the Sydney BIRU were asked to administer the SPIRQ at the end of an occupational therapy session, and then the same occupational therapist conducted a second administration 5-7 days later at the end of an occupational therapy session. All participants with TBI received two sessions of occupational therapy between the two administrations. The interval of approximately $1 \mathrm{wk}$ was considered sufficient to minimize carryover effects yet short enough to reduce the likelihood of actual clinical change occurring (Domholdt, 2005).

\section{Data Analysis}

Data screening procedures identified missing data for 2 participants on a small number of SPIRQ items. These participants were excluded from further analysis. We conducted an exploratory factor analysis of the SPIRQ using principal components analysis with varimax rotation of factors with eigenvalues $>1$. A sample size of at least 100 participants and ratio of 5 participants per item is generally regarded as the minimum for a reliable factor solution (Guadagnoli \& Velicer, 1988; Hatcher, 1994). Internal consistency was assessed using Cronbach's $\alpha$, with the criterion of .70 regarded as acceptable (George $\&$ Mallery, 2003). Item suitability was considered according to Pallant's (2007) guidelines, with an item deemed problematic if at least two of the three following conditions exist: (1) Values for interitem correlations are negative; (2) values for corrected item-total correlations are <.3; and (3) a higher $\alpha$ value would be obtained if the item was excluded. Data screening identified that data on the SPIRQ scales were normally distributed, and we therefore examined test-retest reliability using Pearson's product-moment correlation. We also conducted paired $t$ tests to determine whether scores significantly differed between the two administrations conducted 5-7 days apart (Domholdt, 2005).

\section{Results}

\section{Participant Characteristics}

Participants were 105 patients admitted to BIRUs at major metropolitan hospitals in Brisbane and Sydney. Occupational therapists administered the SPIRQ to all eligible patients with TBI as part of their occupational therapy program. No attrition occurred. At the Brisbane BIRU, 72 patients with TBI were recruited as they received inpatient occupational therapy $(81 \%)$ or outpatient occupational therapy consisting of weekly intervention sessions (19\%). Participants at the Sydney BIRU $(n=33)$ were all receiving inpatient occupational therapy.

The demographic and injury characteristics of the total sample and the subsamples are summarized in Table 2. Participants were in their 1 st yr post-TBI, were predominantly male (79\%), and were on average $36.3 \mathrm{yr}$ old (standard deviation $=13.9)$. The causes of TBI included road traffic accidents $(n=81 ; 77 \%)$, falls $(n=10 ; 10 \%)$, assaults $(n=9 ; 9 \%)$, sporting accidents $(n=3 ; 2 \%)$, and self-inflicted penetrating injuries $(n=2 ; 2 \%)$.

The 33 participants with TBI from the inpatient unit in Sydney were somewhat older than the Brisbane participants and had more recent injuries (Table 2). On the basis of the duration of PTA recorded in medical files,

Table 2. Demographic and Injury Characteristics of the Sample With Traumatic Brain Injury

\begin{tabular}{|c|c|c|c|}
\hline Demographic and Medical Characteristics & Brisbane BIRU $(n=72)$ & Sydney BIRU $(n=33)$ & Total Sample $(N=105)$ \\
\hline Age, $M(S D)$, range & 32.22 (13.6), 18-66 & $40.28(14.1), \quad 18-63$ & 36.25 (13.9), $18-66$ \\
\hline \multicolumn{4}{|l|}{ Gender, $n(\%)$} \\
\hline Male & $(79.2)$ & $(78.8)$ & $(79.0)$ \\
\hline Female & $(20.8)$ & $(21.2)$ & $(21.0)$ \\
\hline Time since injury, months, $M(S D)$, range & $4.81 \quad(2.5), \quad 1-12.0$ & $2.5 \quad(1.48), 0.5-8.0$ & 3.65 (2.0), $0.5-12$ \\
\hline Posttraumatic amnesia duration, days, $M(S D)$, range & $39.55(29.3), \quad 3-154$ & 55.84 (40.8), $\quad 9-180$ & 47.62 (34.2), $\quad 3-180$ \\
\hline Disability Rating Scale, $M(S D)$, range & $4.83 \quad(2.4), \quad 1-12$ & 4.72 (1.1), 3-8 & 4.78 (1.8), \\
\hline
\end{tabular}

Note. BIRU = brain injury rehabilitation unit; $M=$ mean; $S D=$ standard deviation. 
participants had all sustained a severe TBI, although data for PTA were missing for approximately $17 \%$ of the sample. Where PTA data were unavailable, Glasgow Coma Scale (GCS) scores indicated that approximately $8 \%$ of the sample had sustained mild to moderate TBI (GCS > 8/15). Functional status as rated on the Disability Rating Scale was similar between the two samples. The participants with TBI in the Sydney BIRU were involved in the test-retest reliability analysis and received two SPIRQ administrations over a 5- to 7-day interval.

\section{Factor Analysis}

An exploratory factor analysis with varimax rotation resulted in a four-factor solution based on factors with eigenvalues $>1$ and accounted for $56.9 \%$ of the variance. The eigenvalues for each factor and proportion of variance accounted for were as follows: Factor $1=5.70$ (28.5\%); Factor $2=3.00$ (15.0\%), Factor $3=1.42$ (7.1\%), and Factor $4=1.25$ (6.27\%; see Table 3). The first factor extracted included seven items with loadings of .58-.77 and was labeled Changes in Self and Life Plans. The items spanned both the Current Self (three items) and Future Self (four items) scales. The second factor extracted, Emotional Reactions, included all six items of

Table 3. Principal Components Analysis of the Self-Perceptions in Rehabilitation Questionnaire $(N=103)$

\begin{tabular}{|c|c|c|c|c|}
\hline \multirow[b]{2}{*}{ Scales and Items } & \multicolumn{4}{|c|}{ Extracted Factors } \\
\hline & 1 & 2 & 3 & 4 \\
\hline \multicolumn{5}{|l|}{ Current Self } \\
\hline Differences in myself compared with before & .58 & & & \\
\hline Feel I have made a full recovery & & & & .70 \\
\hline Manage everyday tasks the same as before & & & & .60 \\
\hline Need to use more strategies now & .59 & & & \\
\hline Other people notice changes in me & .66 & & & \\
\hline \multicolumn{5}{|l|}{ Future Self } \\
\hline Will affect how well I can do things in life & .77 & & & \\
\hline Will still affect my life in 6 months time & .59 & & & \\
\hline Need to change future plans & .59 & & & \\
\hline Concerned about long-term effects & .73 & & & \\
\hline \multicolumn{5}{|l|}{ Self in Rehabilitation } \\
\hline Helping me to understand the brain injury & & & .73 & \\
\hline $\begin{array}{l}\text { Back to normal if allowed to return to } \\
\text { preinjury activities }\end{array}$ & & & & .66 \\
\hline Learning to cope with the effects of the injury & & & .76 & \\
\hline Working on areas that are important to me & & & .50 & \\
\hline Helping me to achieve my goals & & & .81 & \\
\hline \multicolumn{5}{|l|}{ Emotional Reactions } \\
\hline Feel uneasy about the future & & .68 & & \\
\hline Have self-confidence in my abilities & & .79 & & \\
\hline Worry about progress in rehabilitation & & .48 & & \\
\hline Hopeful about the future & & .62 & & \\
\hline Feel good about myself & & .81 & & \\
\hline Feel like I can't do anything right & & .45 & & \\
\hline
\end{tabular}

the Emotional Reactions scale (item loadings $=.45-.81$ ). That two of the Emotional Reactions items (Item 3 and Item 10$)$ also loaded positively (.51 and .44 , respectively) on the first factor extracted is noteworthy; however, their item loadings were highest on the second factor (.68 and .48 , respectively). The third factor extracted, Self in Rehabilitation, included four items of the Self in Rehabilitation scale (item loadings $=.50-.81$ ).

The fourth and final factor extracted included three items: one from the Self in Rehabilitation scale and two from the Current Self scale (item loadings $=.60-.70$ ). The content of these items suggested that this factor reflected views on recovery or returning to one's premorbid functioning. However, we had concern about treating this factor as a scale for further psychometric analysis because it had only three items, all of which were reverse scored. Hence, the wording of each item required participants to disagree with the statement to acknowledge the consequences of their TBI (e.g., "I feel that I have made a full recovery from my brain injury"). Cronbach's $\alpha$ (.62) for this set of three items was also low. Therefore, because of uncertainty about the valid interpretation of the fourth factor, we excluded these items from further analysis in this study.

\section{Internal Consistency}

Examination of Cronbach's $\alpha$ for the three scales of the SPIRQ identified that $\alpha$ was acceptable $(\alpha>.70)$ for the Changes in Self and Life Plans (7 items, $\alpha=.83$ ), Emotional Reactions $(\alpha=.72)$, and Self in Rehabilitation scales $(\alpha=.80)$. Moreover, the item-total correlations were all positive and greater than $.30(.46-.60, .39-.65$, and .40-.69 for the three scales, respectively), and removing an item would not improve Cronbach's $\alpha$ for any of the scales.

\section{Test-Retest Reliability}

Paired-samples $t$ tests revealed no significant differences between the first and second administration of the SPIRQ for any of the scales over the 5- to 7-day interval for the Sydney inpatient sample $(n=33$; see Table 4$)$. Test-retest reliability was good $(r>.80)$ for the Changes in Self and Life Plans scale and acceptable $(r>.70)$ for the Emotional Reactions scale. The test-retest coefficient was significant for the Self in Rehabilitation scale $(r=.67, p<.001)$, although it was below the acceptable criterion $(r<.70)$.

\section{Associations Between the SPIRQ and Clinical Variables}

The final analysis examined the associations between the SPIRQ scales and injury characteristics. The Changes in Self and Life Plans scale was significantly associated with 


\begin{tabular}{|c|c|c|c|c|c|}
\hline Scale & $r$ & Time 1, $M(S D)$ & Time 2, $M(S D)$ & $t$ & $p$ \\
\hline Changes in Self and Life Plans & $.81^{*}$ & $26.30(7.57)$ & $26.67(8.11)$ & -0.43 & .673 \\
\hline Self in Rehabilitation & $.67^{*}$ & $19.36(2.09)$ & $19.61(1.94)$ & -0.68 & .504 \\
\hline
\end{tabular}

${ }^{*} p<.001$.

the Self in Rehabilitation scale $(r=.34, p<.001)$ and Emotional Reactions scale $(r=.49, p<.001)$, indicating that participants who recognized greater functional consequences of their TBI were more likely to perceive rehabilitation as beneficial and report increased emotional distress. However, the association between the Self in Rehabilitation and Emotional Reactions scales was small and nonsignificant $(r=-0.10, p>.05)$. Responses on the SPIRQ were unrelated to injury characteristics, with one exception; participants with greater time since injury were more likely to perceive changes to self and their life plans $(r=.29, p<.01)$.

\section{Discussion}

The exploratory factor analysis provided some support for the conceptual structure of the SPIRQ, particularly the two scales assessing emotional reactions and perceived benefits of rehabilitation. However, the distinction between Current Self and Future Self was not empirically supported because most of these items loaded onto a single factor, Changes in Self and Life Plans. Internal consistency of the three factor-derived SPIRQ scales was sound. Testretest reliability was generally acceptable, and scores did not significantly differ over the 5- to 7-day readministration interval. Responses on the SPIRQ scales were largely unrelated to injury characteristics, although participants with greater time since injury were more likely to perceive the functional consequences of their TBI on the Changes in Self and Life Plans scale.

An interesting finding of this study is that participants' perceptions of their current functioning (e.g., changes in abilities and the need to use strategies) were not distinguishable from their perspectives on the future impact of their TBI. Instead, a single factor (Changes in Self and Life Plans) best accounted for their views on their current and future functioning. However, two items developed to assess current self did not load onto this factor. Specifically, "I feel I have made a full recovery from my brain injury" and "I manage everyday tasks the same as how I used to before my brain injury" loaded onto a fourth factor. This fourth factor also included one item from the Self in Rehabilitation scale ("I would be back to normal if I was allowed to return to all the things I used to do, e.g. driving, work, playing sports"). These three items appear to reflect views on recovery and returning to "normal" that have previously been found to be a major theme of adjustment during this period (Turner, Ownsworth, Cornwell, \& Fleming, 2009). Agreement on these items may also reflect that participants were in the precontemplation stage of change in terms of their treatment readiness (see Lam et al., 1988).

Despite the potential relevance of these self-perceptions to rehabilitation, we were concerned about forming a scale based on only three items. Moreover, these items possibly loaded on the same factor because of the response format rather than a shared meaning. Further research is needed to ascertain whether self-perceived views on recovery and returning to normal represent a distinct construct to assess during rehabilitation by generating more items related to this theme and wording items as both positive and negative statements.

The findings indicated that the internal consistency and test-retest reliability of the three SPIRQ scales were mainly in the acceptable to good range (Tate, 2010). Both forms of reliability were strongest for the Changes in Self scale, which also had the most items (seven). The Self in Rehabilitation scale had the fewest items (four) and demonstrated less stability over the 5- to 7-day reassessment interval. This scale assesses the extent to which participants feel that they are learning to understand and cope with the effects of their brain injury as well as working on areas of personal importance and achieving their goals in rehabilitation. The somewhat lower testretest reliability for this scale may indicate that perceptions of the benefits of occupational therapy rehabilitation can fluctuate over a short period of time during inpatient rehabilitation.

Responses on the SPIRQ scales did not vary according to injury severity (PTA) or functional status on the Disability Rating Scale. This finding is broadly consistent with research on self-awareness within populations with moderate to severe TBI, suggesting that clients' subjective appraisals of their injury and the functional consequences are typically unrelated to indices of injury severity (Fleming \& Strong, 1999). Responses on the Changes in Self and Life Plans scale were positively related to time 
since injury, reinforcing previous findings that, with time, people are better able to make sense of their postinjury impairments and the long-term implications (Godfrey et al., 1993; Hart et al., 2009). Moreover, participants who reported greater functional consequences of their TBI were more likely to perceive rehabilitation as beneficial and report increased emotional distress. This pattern mirrors previous findings that people with high self-awareness report greater levels of both motivation and emotional distress than people with low self-awareness (Fleming et al., 1998). The lack of association between the Self in Rehabilitation and Emotional Reactions scales suggests that emotional distress is not uniformly related to higher or lower appraisals concerning the benefits of participating in rehabilitation.

The direction of associations between the SPIRQ scales cannot be assumed because of the cross-sectional data. Hence, the pattern of responses on the SPIRQ and associations between the scales need to be investigated over an extended time period, for example, from admission to discharge. Related to this, an important future objective for validating the SPIRQ involves assessing the tool's sensitivity, or capacity to detect clinically meaningful change in the context of rehabilitation (Domholdt, 2005).

\section{Limitations and Future Research}

Several other methodological issues need to be considered in this preliminary study. As with all self-report measures, responses on the SPIRQ are prone to self-report biases that may affect the validity of information gained. Future research needs to examine the extent to which SPIRQ responses are influenced by potential sources of bias, including social desirability, denial, and memory impairment. In terms of sampling and related validity considerations, the occupational therapists administered the SPIRQ to all eligible inpatients with TBI, and hence the sample is likely to be broadly representative of patients receiving inpatient rehabilitation. However, the characteristics of patients with TBI differed between the two services (i.e., age and time since injury) and may indeed differ from other settings. Because only a small number of outpatients were included, further research is needed to examine the reliability of the SPIRQ for outpatient rehabilitation and across different postacute rehabilitation settings.

The sample size of just more than 100 participants is considered the minimum for exploratory factor analysis (Hatcher, 1994), and the factor solution and item loadings might change with the addition of more participant data. Accordingly, the stability of this solution needs to be examined in future research using a larger sample with TBI (i.e., >200). Additionally, both the convergent and the divergent validity of the SPIRQ require investigation to provide further indication of the tool's construct validity. Another key priority for future research is to examine the SPIRQ's sensitivity to change in hospital-based rehabilitation as well as in response to particular interventions (e.g., self-awareness training).

Although further psychometric evaluation is warranted before clinical use, the potential applications of the SPIRQ may be considered. The tool may assist in detecting the emergence of self-awareness, which often occurs during the early community reintegration period (Fleming \& Strong, 1999). The SPIRQ may also help to identify people who begin to overestimate the functional consequences of their TBI relative to objective indices, which is commonly associated with emotional distress and poorer long-term functional outcomes (Ownsworth et al., 2007). Therefore, to support accurate interpretation of responses, the SPIRQ is intended as a supplement to other measures that provide more objective indices of functioning. For example, clients who report only minor consequences of TBI on the Changes in Self and Life Plans scale may do so because they experience only mild functional deficits. It is therefore necessary to interpret clients' responses on the SPIRQ in the context of their current functional status.

The client-centered, occupation-based, and goaldirected emphasis of occupational therapy means issues of self-awareness and motivation for rehabilitation are highly relevant (Doig, Fleming, Cornwell, \& Kuipers, 2009). Therefore, use of the SPIRQ in the context of occupational therapy may be particularly appropriate. However, the SPIRQ may also have value as an instrument administered with a multidisciplinary rehabilitation team focus, and therefore the SPIRQ's reliability and validity need to be specifically examined in this context in the future.

\section{Implications for Occupational Therapy Practice}

The results of this study have the following implications for occupational therapy practice:

- In postacute rehabilitation, evaluation of self-perceptions of clients with TBI may assist occupational therapists in understanding their readiness to engage in therapy.

- The SPIRQ is a brief scale designed to periodically monitor clients' self-perceptions, motivation, and emotional reactions related to therapy.

- Monitoring changes over time on the SPIRQ scales (Changes in Self and Life Plans, Self in Rehabilitation, and Emotional Reactions) could enhance the clientcenteredness of occupational therapy practice. 


\section{Conclusion}

In summary, the SPIRQ was designed as a brief tool to provide occupational therapists with the option to periodically monitor clients' self-perceptions, motivation, and emotional reactions during TBI rehabilitation. By administering the SPIRQ at different time points throughout rehabilitation, occupational therapists may be better informed about a client's readiness to engage in particular therapy components (e.g., goal setting, receiving feedback) and the need to address issues that could impede progress in rehabilitation, including a lack of understanding of the benefits of rehabilitation and the emergence of emotional distress. Further research is needed before clinical use that involves examining the SPIRQ's construct validity and sensitivity to change as well as its potential application for use by a multidisciplinary rehabilitation team.

\section{Acknowledgments}

We gratefully acknowledge the occupational therapists and patients at both brain injury rehabilitation units.

\section{References}

Abreu, B. C., Seale, G., Scheibel, R. S., Huddleston, N., Zhang, L., \& Ottenbacher, K. J. (2001). Levels of selfawareness after acute brain injury: How patients' and rehabilitation specialists' perceptions compare. Archives of Physical Medicine and Rehabilitation, 82, 49-56. http:// dx.doi.org/10.1053/apmr.2001.9167

Dirette, D. (2002). The development of awareness and the use of compensatory strategies for cognitive deficits. Brain Injury, 16, 861-871. http://dx.doi.org/10.1080/ 02699050210131902

Doig, E., Fleming, J., Cornwell, P. L., \& Kuipers, P. (2009). Qualitative exploration of a client-centered, goal-directed approach to community-based occupational therapy for adults with traumatic brain injury. American Journal of Occupational Therapy, 63, 559-568. http://dx.doi.org/ 10.5014/ajot.63.5.559

Domholdt, E. (2005). Rehabilitation research: Principles and applicants (3rd ed.). St. Louis, MO: Elsevier.

Felmingham, K. L., Baguley, I. J., \& Crooks, J. (2001). A comparison of acute and postdischarge predictors of employment 2 years after traumatic brain injury. Archives of Physical Medicine and Rehabilitation, 82, 435-439. http:// dx.doi.org/10.1053/apmr.2001.21985

Fleming, J. M., \& Strong, J. (1999). A longitudinal study of self-awareness: Functional deficits underestimated by persons with brain injury. OTJR: Occupation, Participation and Health, 19, 3-17.

Fleming, J. M., Strong, J., \& Ashton, R. (1996). Self-awareness of deficits in adults with traumatic brain injury: How best to measure. Brain Injury, 10, 1-15. http://dx.doi.org/10. 1080/026990596124674
Fleming, J. M., Strong, J., \& Ashton, R. (1998). Cluster analysis of self-awareness levels in adults with traumatic brain injury and relationship to outcome. Journal of Head Trauma Rehabilitation, 13, 39-51. doi:10.1097/00001199199810000-00006

Fleming, J. M., Winnington, H. T., McGillvray, A. J., Tatarevic, B. A., \& Ownsworth, T. L. (2006). The development of self-awareness and relationship to emotional functioning during early community reintegration after traumatic brain injury. Brain Impairment, 7, 83-94. http://dx.doi. org/10.1375/brim.7.2.83

George, D., \& Mallery, P. (2003). SPSS for Windows step by step: A simple guide and reference. 11.0 update (4th ed.). Boston: Allyn \& Bacon.

Godfrey, H. P. D., Partridge, F. M., Knight, R. G., \& Bishara, S. (1993). Course of insight disorder and emotional dysfunction following closed head injury: A controlled cross-sectional follow-up study. Journal of Clinical and Experimental Neuropsychology, 15, 503-515. http://dx.doi. org/10.1080/01688639308402574

Guadagnoli, E., \& Velicer, W. F. (1988). Relation of sample size to the stability of component patterns. Psychological Bulletin, 103, 265-275. http://dx.doi.org/10.1037/00332909.103.2.265

Hart, T., Seignourel, P. J., \& Sherer, M. (2009). A longitudinal study of awareness of deficit after moderate to severe traumatic brain injury. Neuropsychological Rehabilitation, 19, 161-176. http://dx.doi.org10.1080/09602010802188393

Hatcher, L. (1994). A step-by-step approach to using the SAS system for factor analysis and structural equation modeling. Cary, NC: SAS Institute.

Lam, C. S., McMahon, B. T., Priddy, D. A., \& GehredSchultz, A. (1988). Deficit awareness and treatment performance among traumatic head injury adults. Brain Injury, 2, 235-242. http://dx.doi.org./0.3109/ 02699058809150947

Law, M., Baptiste, S., Carswell, A., McColl, M. A., Polatajko, H., \& Pollock, N. (1998). The Canadian Occupational Performance Measure (3rd ed.). Ottawa, ON: CAOT.

Nunnally, J. C. (1967). Psychometric theory (1st ed.). New York: McGraw-Hill.

Ownsworth, T., \& Clare, L. (2006). The association between awareness deficits and rehabilitation outcome following acquired brain injury. Clinical Psychology Review, 26, 783-795. http://dx.doi.org/10.1016/j.cpr.2006.05.003

Ownsworth, T., Fleming, J., Desbois, J., Strong, J., \& Kuipers, P. (2006). A metacognitive contextual intervention to enhance error awareness and functional outcome following traumatic brain injury: A single-case experimental design. Journal of the International Neuropsychological Society, 12, 54-63. http://dx.doi.org/10.1017/S135561770606005X

Ownsworth, T., Fleming, J., Haines, T., Cornwell, P., Kendall, M., Nalder, E., \& Gordon, C. (2011). Development of depressive symptoms during early community reintegration after traumatic brain injury. Journal of the International Neuropsychological Society, 17, 112-119. http://dx. doi.org/10.1017/S1355617710001311

Ownsworth, T. L., Fleming, J., Stewart, E., \& Griffin, J. (2009, August). The Self-Perceptions in Rehabilitation Questionnaire: A 
new measure of brain injury rehabilitation progress. Presentation at the 6th Satellite Symposium on Neuropsychological Rehabilitation, Tallin, Estonia.

Ownsworth, T., Fleming, J., Strong, J., Radel, M., Chan, W., \& Clare, L. (2007). Awareness typologies, long-term emotional adjustment and psychosocial outcomes following acquired brain injury. Neuropsychological Rehabilitation, 17, 129-150. http://dx.doi.org/10.1080/ 09602010600615506

Ownsworth, T. L., McFarland, K. M., \& Young, R. M. (2000). Development and standardization of the SelfRegulation Skills Interview (SRSI): A new clinical assessment tool for acquired brain injury. Clinical Neuropsychologist, 14, 76-92. http://dx.doi.org/10.1076/1385-4046(200002)14: 1;1-8;FT076

Pallant, J. F. (2007). SPSS survival manual: A step-by-step guide to data analysis using SPSS. Crows Nest, New South Wales, Australia: Allen \& Unwin.

Prigatano, G. P., Fordyce, D., Zeiner, H., Roueche, J., Pepping, M., \& Wood, B. (1986). Neuropsychological rehabilitation after brain injury. Baltimore: Johns Hopkins University Press. Sherer, M., Bergloff, P., Boake, C., High, W., Jr., \& Levin, E. (1998). The Awareness Questionnaire: Factor structure and internal consistency. Brain Injury, 12, 63-68. http:// dx.doi.org/10.1080/026990598122863

Sherer, M., Bergloff, P., Levin, E., High, W. M., Jr., Oden, K. E., \& Nick, T. G. (1998). Impaired awareness and employment outcome after traumatic brain injury. Journal of Head Trauma Rehabilitation, 13, 52-61. http://dx.doi. org/10.1097/00001199-199810000-00007

Tate, R. (2010). A compendium of tests, scales and questionnaires: The practitioner's guide to measuring outcomes after acquired brain injury. Hove, England: Psychology Press.

Tate, R. L., \& Broe, G. A. (1999). Psychosocial adjustment after traumatic brain injury: What are the important variables? Psychological Medicine, 29, 713-725. http://dx.doi. org/10.1017/S0033291799008466

Toglia, J., \& Kirk, U. (2000). Understanding awareness deficits following brain injury. NeuroRehabilitation, 15, 57-70.

Turner, B., Ownsworth, T., Cornwell, P., \& Fleming, J. (2009). Reengagement in meaningful occupations during the transition from hospital to home for people with acquired brain injury and their family caregivers. American Journal of Occupational Therapy, 63, 609-620. http://dx. doi.org/10.5014/ajot.63.5.609 